\title{
UM CORPO QUE HABITA É CAPAZ DE (RE)PENSAR HÁBITOS: REFLEXÕES PARA O TURISMO PÓS-PANDEMIA
}

\author{
AN INHABITING BODY IS ABLE TO (RE)THINK HABITS: RETHINKING \\ POST PANDEMIC TOURISM
}

\author{
Newton Fernandes de Ávila \\ Universidade de Caxias do Sul, UCS. \\ nfavila@ucsc.br \\ https://orcid.org/0000-0002-0304-1321 \\ Maria Luiza Cardinale Batista \\ Universidade de Caxias do Sul, UCS. \\ malu@pazza.com.br \\ https://orcid.org/0000-0002-7096-1160
}

Recibido/Received: 30/04/2021

Modificado/Modified: 06/10/2021

Aceptado/Accepted: 13/12/2021

\section{RESUMO}

Este texto apresenta narrativas transversais sensíveis, com relatos de sujeitos em lugares turísticos, transversalizando temáticas: corpo que habita, hábitos, território habitado e futuro do Turismo frente à Pandemia COVID-19. Decorre de estudo transdisciplinar, qualitativo, com fundamentação teórica sobre: Esquizoanálise; Biologia; Ecossistemas Turísticos; Comunicação-trama; Jornalismo Literário Avançado; Estudos de Narrativas; Sintaxe da Linguagem Visual. A estratégia metodológica é a Cartografia dos Saberes, de Baptista, de cunho qualitativo, processual e plurimetodológico, na proposição de trilhas (Saberes Pessoais, Saberes Teóricos, Usina de Produção e Dimensão Intuitiva da Pesquisa) e realização de aproximações investigativas e ações investigativas. As narrativas transversais sensíveis, em 'comversações' de sujeitos e lugares turísticos, ajudam a compreender o corpo como lugar de vida, pulsante, vibrátil, em contribuição para pensar o futuro do Turismo.

\section{PALAVRAS CHAVE}

Turismo. Comunicação. Narrativas transversais. Autopoiese. Amorosidade.

\section{SUMARIO}

1. Introdução. 2. 'Com-versações' teóricas. 3. Metodologia. 4. Resultados e Discussão. 5. Considerações finais. 6. Referências.

\begin{abstract}
This text presents sensitive transversal narratives, with reports of subjects in tourist places, transversalizing themes: body that inhabits, habits, inhabited territory and future of Tourism in face of the COVID-19 Pandemic. It results from a transdisciplinary, qualitative study, with theoretical foundation on: Schizoanalysis; Biology; Tourist Ecosystems; Communication-plot; Advanced Literary Journalism; Narrative Studies; Visual Language Syntax. The methodological strategy is the Cartography of Knowledge, by Baptista, of a qualitative, procedural and plurimetodological nature, in the proposition of trails (Personal Knowledge, Theoretical Knowledge, Production Plant and Intuitive Dimension of Research) and carrying out investigative approaches and investigative actions. The sensitive transversal
\end{abstract}


narratives, in 'com-versations' of subjects and tourist places, help to understand the body as a place of life, pulsating, vibrating, in contribution to think about the future of Tourism.

\section{KEYWORDS}

Tourism. Communication. Cross-sectional narratives. Autopoiesis. Amorosity.

\section{CONTENTS}

1. Introduction. 2. Theoretical 'con-versations'. 3. Methodology. 4. Results and discussion. 5. Final considerations. 6. References.

\section{INTRODUÇÃ̃O}

Este presente texto versa sobre narrativas transversais sensíveis, a partir de relatos de sujeitos em lugares turísticos, propondo um diálogo entre o corpo que habita, os hábitos, o território habitado e o futuro do Turismo frente à Pandemia COVID-19. Narrativas transversais sensíveis é um termo proposto por Baptista (2020a) e correspondem a uma proposição de narrativas, a partir da ampliação da sensibilidade e da transcodificação e de dispositivos comunicacionais, o que implica uma coleta variada, envolvendo escuta sensível, produção e coleta de entrevistas e 'com-versações' midiáticas. Essa proposição relaciona-se ao Jornalismo Literário Avançado, conforme vem sendo proposto por Edvaldo Pereira Lima (2009; 2013), e desenvolvido por Mônica Martinez (2012; 2019), entre outros autores.

Considera-se também, no texto, a noção de Corpoiesis, segundo a qual o corpo é pensado como campo de produção de sentidos e de reinvenção. Corpo como platô existencial, no sentido esquizoanalítico, o que implica pensar corpos-sujeitos e corpos-lugares turísticos. Trata-se de um estudo transdisciplinar, qualitativo, envolvendo, como fundamentação teórica, especialmente, estudos sobre: Esquizoanálise, com Félix Guattari e Suely Rolnik; Biologia (Amorosa e do Conhecimento), com Humberto Maturana e Francisco Varela; Turismo, na perspectiva da complexidade ecossistêmica, como os de Maria Luiza Cardinale Baptista (2014a; 2014b); e Mario Carlos Beni e Marutschka Moesch; Comunicação-trama, com Maria Luiza Cardinale Baptista; Jornalismo Literário Avançado, com Edvaldo Pereira Lima; Estudos de Narrativas, por Monica Martinez, Demétrio de Azeredo Soster e Fabiana Piccinin; Sintaxe da Linguagem Visual, de Donis Dondis e Martine Joly.

A estratégia metodológica utilizada é a Cartografia de Saberes, proposta por Baptista (2014c), um dispositivo científico de investigação, com orientação qualitativa, plurimetodológico e processual. Trata-se de proposição metodológica, na confluência entre a Esquizoanálise, como referência epistemológico-teórica: com a perspectiva da Complexidade de Edgar Morin; da Ciência da Mutação e Holística, de Fritjof Capra e Roberto Crema; da Visão Ecossistêmica, inspirada em Gilson Monteiro e Sandro Colferai; das Estruturas Dissipativas de Ilya Prigogine. A Cartografia propõe trilhas (Saberes Pessoais, Saberes Teóricos, Usina de Produção e Dimensão Intuitiva da Pesquisa) e busca a realização de aproximações e ações investigativas. O caráter plurimetodológico possibilita utilizar procedimentos vários, desde os já amplamente utilizados - como levantamento bibliográfico, observação direta, observação participante, rodas de conversa, relatos de vivências etc., até outros criados especificamente para a abordagem de um determinado objeto de estudo. 
O texto deriva de pesquisas que estão sendo realizadas no Sul do Brasil, na Universidade de Caxias do Sul, em Projetos do Amorcomtur! Grupo de Estudos em Comunicação, Turismo, Amorosidade e Autopoiese: 1) 'Com-versar' Amorcomtur - Lugares e Sujeitos! Narrativas transversais sensíveis, envolvendo sujeitos em processos de desterritorialização - Brasil, Espanha, Portugal, Itália, México, Colômbia, Egito, Omã e Índia. 2) Ecossistemas Turístico-Comunicacionais-Subjetivos: Sinalizadores teórico-metodológicos, no estudo de ecossistemas turístico-comunicacionais-subjetivos, considerados a partir de sua característica ecossistêmica, caosmótica e autopoiética. 3) Trama Comunicacional e Corpoiesis na Reinvenção de Sujeitos e Lugares Turísticos.

As reflexões produzidas para este artigo partem da escuta sensível de narrativas transversais sensíveis em 'com-versações' de sujeitos e lugares turísticos, abordando o corpo como um lugar de vida, pulsante, vibrátil. Sujeitos de diversos lugares, de variadas profissões, moradores de diferentes cidades do sul do Brasil (Rio Grande do Sul, Santa Catarina e Paraná), que aceitaram responder no mês de dezembro de 2020 uma pergunta aberta enviada via WhatsApp e pontuar suas observações referente às relações dos sujeitos e do Turismo entremeadas à Pandemia COVID-19.

\section{2. 'COM-VERSAÇÕES' TEÓRICAS}

Para a abordagem do problema expresso no objeto de estudo narrativas transversais sensíveis, a partir de relatos de sujeitos em lugares turísticos, propondo um diálogo entre o corpo que habita, os hábitos, o território habitado e o futuro do Turismo frente à Pandemia COVID-19, algumas trilhas teóricas são mais significativas. Como sinalizador narrativo, temos o título 'Um corpo que habita é capaz de (re)pensar hábitos: reflexões para o Turismo Pós-Pandemia'. Por isso, este item está estruturado com a apresentação dos percursos teóricos, partindo da trilha teórico-conceitual 'corpo'.

Nos estudos que realizamos, o corpo é considerado a partir do fato de que é um corpo vivo desde que nasce, seja corpo humano ou não. Desta forma, pode-se pensar o "corpo como ponto de partida e chegada de toda comunicação humana", como refere Baitello Júnior (TvPuc, 2013). Complementando essa afirmação, o autor, em outro texto, expõe que, “[...] corpos nascem de outros corpos e se alimentam de outros corpos. Assim, a rigor, todo gesto reprodutor do corpo pressupõe uma doação de si mesmo para o novo ser em formação" (Baitello Júnior, 2002). Se um corpo se transforma, ele adquire outros olhares e pode ver e agir de outra forma, seja no trabalho, seja no turismo.

O corpo aqui, então, é considerado além de um corpo físico, ele é também pensado em seu interior e seu exterior, com sentimentos e emoções. Um corpo que produz, um centro de energias, corpo vibrátil, que pulsa, no sentido proposto pela Esquizoanálise (Guattari \& Rolnik, 1996). A Esquizoanálise foi desenvolvida pelo filósofo francês Gilles Deleuze e pelo filósofo, psicanalista e militante revolucionário francês Félix Guattari, inicialmente no livro 'O Anti-Édipo', em 1972, e depois no projeto intitulado 'Mil Platôs', publicação em uma coleção de livros, inicialmente em 1980. Nessa proposição, o corpo é pensado como lugar de vida e, neste sentido, envolve, sujeito e lugar. O sujeito é um corpo, bem como o lugar é um corpo vibrátil, um campo de energias, engendramentos de processos e pulsação de vida. Os dois demandam cuidados e olhares.

O que se propõe, neste texto, relaciona-se com o sentido de observar um corpo em movimento, vibrátil, numa trama comunicacional, enredada pela comunicação e pela convivência coletiva, por meio de suas relações (relações com o lugar, com o 'outro', com 
o ecossistema num todo). A trama referida é uma trama de relações (em comunicação, na convivência com o 'outro' e também ecossistêmica científica). Corresponde a conceito trama, proposto por Baptista $(1996 ;$ 2000). Essa condição Corpoiesis, de autoprodução constante, demanda amor, sendo decorrente de processos intensos, delicados e complexos. São processos fundamentais, porque constituem-se como base de sobrevivência humana, mais que isso, sobrevivência dos ecossistemas todos, dos corpos em suas múltiplas expressões.

A proposição Corpoiesis surgiu do entrelaçamento das palavras corpo + autopoiese, esta última cunhada por Humberto Maturana e Francisco Varela (1997) que concebem a proposição como um processo de autoprodução como ações coordenadas na célula. Expressam, dessa forma, que os seres vivos produzem a si próprios através de mecanismos autorreguladores de um sistema fechado. Já Autopoiese significa, neste texto, a capacidade de fazer com que o sujeito e também o lugar, se (re)veja, se (re)organize, se (re)descubra e se (re)construa, potencializando para comunicar, se relacionar e crescer. Inspirada em Maturana, Baptista (2019: 73) complementa que a autopoiese "[...] se faz no encontro, no entrelaçamento, nas redes de afetos e vínculos, no 'refazendo', no processo de vivenciar o 'estar junto', a convivência".

$\mathrm{O}$ conceito de Corpoiesis tem vinculações à ideia de autopoiese, mas também ao entendimento de amor, por Maturana. $\mathrm{O}$ autor afirma se tratar de emoção fundamental, que tornou possível a história da humanidade e que determina condutas humanas e tece o convívio social. Maturana, na mesma entrevista a Reis (2016) ainda complementa que "[...] apesar de vivermos um momento de negação do amor, só sobrevivemos porque essa emoção persiste nos vínculos que definem a vida em sociedade. É no amor que alcançamos o bemestar e realizamos nossa condição humana”. Dessa forma, é possível pensar que é também o amor que dá a possibilidade de compartilhar a vida e viver experiências com outras pessoas.

Outra trilha teórico-conceitual é o Turismo, como processo subjetivo de deslocamento de um lugar para outro, tem sido descrito, em grande parte das vezes, segundo uma lógica funcionalista, pragmática e utilitarista, no sentido de se limitar a apresentar mecanismos e características da ocorrência turística. Mesmo tendo havido transformação no seu conceito, é apresentado, com frequência, na perspectiva desenvolvimentista e produtivista, ligadas ao mercado, às lógicas das cadeias de produção e serviços turísticos. Essas abordagens e perspectivas, envolvendo saberes e fazeres turísticos, confrontam-se com o ponto de crise, com o qual nos deparamos no século XXI, hoje percebido claramente com a Pandemia COVID-19, colocando em risco a relação entre moradores e visitantes de lugares, turísticos ou não.

Partindo dessa compreensão, explicita-se outra lógica de Turismo -o avesso do Turismoindo ao lado contrário da massificação turística e capitalística, na construção de um Turismo pautado pela Responsabilidade Ecossistêmica, alinhado aos 17 Objetivos de Desenvolvimento Sustentável da ONU (Organização das Nações Unidas). Nesse pensar, a Ciência não deve ser produzida apenas para o bem da humanidade, mas para a sobrevivência do ecossistema todo. Igualmente, o Turismo - pensando em um Turismo Pós-Pandemiadeve se pautar pela ética da relação e o cuidado com todos os sujeitos e elementos envolvidos em suas práticas, sendo que esses -sujeitos e elementos- extrapolam o universo dos humanos. Nesse sentido, ao fazer a correlação entre sujeitos, lugar e turismo, é possível concordar com a visão de Turismo, proposta por Beni e Moesch (2017: 453), que consideram o turismo como processo humano, que "[...] ultrapassa o entendimento como função de um sistema econômico. Como um processo singular, necessita de ressignificação às relações impositivas, aos códigos capitalísticos e aos valores colocados como bens culturais". Na 
lógica ecossistêmica, mais recentemente apresentada por esses autores, reconhece-se a ampliação do processo, para além do humano.

No Amorcomtur!, o Turismo vem sendo pensado como Turismo-Trama, ou como Ecossistemas Turísticos. Dessa linha de pensamento, deriva a compreensão dos ecossistemas turístico-comunicacionais-subjetivos como processos complexos de desterritorializações, envolvendo o acionamento e entrelaçamentos de diferentes ecossistemas, em que o sujeito que se desloca é também sujeito de transposições e transversalizações ecossistêmicas, que agencia a movimentação e conexão de mundos, de universos de significações, de referências, de produção e consumo. A complexidade dos ecossistemas turístico-comunicacionais-subjetivos expressa-se, como afirma Baptista (2020b: 49) em outro texto, porque há o envolvimento e o acionamento de "[...] uma teia de materialidades e imaterialidades, desde as potentes tramas econômico-político-sociaisculturais e de prestação de serviços, até os subjacentes fluxos de energias, das micropartículas, de acionamento quântico, que atingem também os níveis de afetos". Com o turismo, tudo se movimenta e se transforma, ao mesmo tempo que o movimento de desterritorialização, em si, autopoietiza (reinventa) sujeitos e lugares, das dimensões ecossistêmicas envolvidas.

Em se tratando de comunicação, Edvaldo Pereira Lima (2020) em sua fala de comunicação construtiva expõe que "Toda mensagem de comunicação produz algum tipo de efeito intelectual, emocional e de consciência no receptor". Nisso podemos perceber que o amor, a amorosidade, construída na convivência é tão fundamental para que se estabeleçam relações com vínculos fortes e produtivos para a reinvenção de sujeitos e de lugares. A comunicação reportada é uma comunicação sensível que demanda escuta, cuidado e acolhimento. Já o termo "Narrativas transversais sensíveis", é proposto por Baptista (2020a), com vistas a uma captação mais sensível e plural dos dados de campo e à produção de relatos com narrativas mais próximas da literatura e da arte, com fortes traços dos sujeitos envolvidos em sua produção. Tem fundamentação geral no Jornalismo Literário Avançado, de Edvaldo Pereira Lima (2009), e na Nova Teoria da Comunicação, de Ciro Marcondes Filho (2010) e no conceito de Bios Midiático, de Muniz Sodré (2006).

As narrativas transversais são produzidas a partir das visualidades que conversam com as narrativas das pessoas e com o olhar do pesquisador, entremeando fotografias e autores, buscando elementos de materialidade que compõem o que Yázigi (2001) chama de "A alma do lugar", agenciando a potencialidade de amorosidade e autopoiese dos sujeitos. Por meio das narrativas, pode haver ensinamentos e orientações entre sujeitos sobre o mundo e seus modos de viver e interagir. Igualmente, "quando nos deparamos com as narrativas de outros, sobre a vida dos outros, podemos receber um convite para atravessar as pontes/portas que nos levam tanto ao afeto como ao vínculo" (Martinez \& Heidemann, 2019: 9). Assim, narrar pode significar trocar experiências, aprender e apreender. Lima (2009) corrobora dizendo que ao narrar um conjunto de acontecimentos, esses são captados e podem trazer uma nova percepção e também outra compreensão do mundo que os rodeia. Complementa ainda Soster e Picinnin (2019: 8) que "narrar é, pois, algo inerente à humanidade e, num certo sentido, tão antigo quanto a própria humanidade. Narrar torna a humanidade humana".

Assim, pode-se dizer que as narrativas transversais sensíveis abarcam uma comunicação diferente e um turismo consciente, ambos vistos pelo avesso, no sentido em que Baptista propõe e consideramos no Amorcomtur!. No avesso, estão as amarras mais profundas, os fios soltos, os nós e entrelaços. No avesso, há as tramas das tessituras que compõem a realidade, sem maquiagem, sem máscaras, sem disfarces. O Avesso é que segura a trama da existência, seja do corpo, seja do turismo, seja da comunicação. Nesse sentido, a proposição 
de avesso, o outro lado do trançado, é apresentada na contramão das relações impositivas, da massificação turística e capitalística, na construção de um Turismo pautado pela Responsabilidade Ecossistêmica, alinhado aos 17 Objetivos de Desenvolvimento Sustentável da ONU (Organização das Nações Unidas).

\section{METODOLOGIA}

A estratégia metodológica utilizada é a Cartografia de Saberes (Baptista, 2014c), um dispositivo científico de investigação, com orientação qualitativa, processual e plurimetodológica, em termos de procedimentos. Corresponde a outro modo de produzir Ciência, a partir de interações múltiplas e de processos geradores de leitura ampliada da realidade, considerando seu caráter complexo ecossistêmico. Procura romper com a separação de sujeito e objeto na pesquisa, trazendo instrumentos de proximidade diferenciados para se fazer ciência, traduzindo o caminho do pensamento e a prática exercida na abordagem da realidade, com base o conceito de cartografia. Nessa perspectiva metodológica, Baptista (2014c) diz que o que realmente importa é a mobilização dos sujeitos investigadores, produtores de Turismo, com uma orientação metodológica mais humana. A autora propõe que o trabalho da pesquisa deve ser iniciado em várias frentes, em várias 'trilhas investigativas'. São elas: Saberes Pessoais (conhecimento prévio do pesquisador sobre determinado assunto advindo de suas vivências e experiências), Saberes Teóricos (aprofundamento teórico sobre o objeto pesquisado), Usina de Produção (propõe o envolvimento do investigador, para criar situações que deem vida à pesquisa, em aproximações e ações investigativas) e Dimensão Intuitiva da Pesquisa (transversalizando todo o processo). As trilhas envolvem aproximações e ações investigativas, num espectro amplo pautado pela qualidade, esmero e sensibilidade da coleta, processamento de dados, análise e produção de relato da investigação.

Com isso, o pesquisador é um cartógrafo na construção de sua pesquisa. O cartógrafo tem a tarefa de dar voz aos sentimentos que pedem passagens (Rolnik, 2011). Cartografar, para Baptista (2014c) com base em Rolnik (2011), é construir mapas, uma espécie de mapeamento, que irão dar direcionamento a partir da capacidade de percepção do pesquisador. Nesse sentido, a proposição se alinha ao pensamento trazido por Morin (2004) em que o conhecimento está sempre em movimento, evidencia a percepção e, pode-se dizer, é seguido constantemente de uma reconstrução.

A Cartografia de Saberes trata-se ainda de proposição metodológica, na confluência entre a Esquizoanálise, como referência epistemológico-teórica: com a perspectiva da Complexidade de Morin (1991; 2012; 2013); da Ciência da Mutação e Holística, de Capra (1991; 2006) e Crema (1989); da Visão Ecossistêmica, inspirada em Monteiro e Colferai (2011); das Estruturas Dissipativas de Prigogine (2001). A Cartografia de Saberes, em sua execução, não considera a possibilidade de separar sujeito e objeto na pesquisa.

A combinação entre o trabalho teórico e os diversos procedimentos operacionais de investigação permite perceber alguns sinalizadores, para a construção da amorosidade e autopoiese e do que, no Amorcomtur!, chamamos 'avesso do turismo', a partir da proposição de Baptista, ou seja, Turismo pautado pela Responsabilidade Ecossistêmica e que se alinha aos objetivos da Agenda 2030. Para a produção deste texto, na confluência operacional de pesquisas, já mencionadas, que estão sendo realizadas no Amorcomtur!, os procedimentos e aproximações e ações investigativas envolveram: cartografia bibliográfica, rodas de 
conversas Amorcomtur!, sobre as temáticas das pesquisas, seminários teóricos, produção e coleta de fotografias, coleta de depoimentos e narrativas de moradores de diversas cidades, produção de textos-conversa com os autores.

A seguir, relata-se na trilha Usina de Produção, da Cartografia de Saberes, a proposição de pensar um corpo que habita um lugar e que pode e é capaz de (re)pensar os hábitos. Direciona então, este texto a, daqui em diante, apresentar 'com-versações' de sujeitos do sul do Brasil, de diferentes lugares e profissões, com reflexões produzidas a partir da escuta sensível de narrativas. Os sujeitos aceitaram responder, no mês de dezembro de 2020, uma pergunta aberta enviada via WhatsApp e a pontuar suas observações referentes às relações dos sujeitos e do Turismo, entremeadas à Pandemia COVID-19. No diálogo, encontrar-seão relatos e conversação com autores, no entrelaçamento de pensar e (re)pensar a vida pessoal, profissional e turística.

A pergunta aberta foi a seguinte: "Como você percebeu em seu trabalho a relação entre as pessoas nessa pandemia (mudou alguma coisa? o que mudou?) e como sentiu que as pessoas reagiram na pandemia, em se tratando do turismo (houve alguma alteração de procura em sua cidade e houve alguma alteração da forma de agir das pessoas na cidade)?"

Foram quatorze os respondentes, com seus relatos transcritos na íntegra, porém, devido ao espaço, no artigo, serão trazidos somente 7 relatos, para ajudar a refletir sobre o futuro. São pessoas com idades de 38 a 63 anos, de diferentes profissões, de cidades da região sul do Brasil (nos estados do Rio Grande do Sul, Santa Catarina e Paraná).

A partir de agora, apresentamos o 'com-versar', com as narrativas transversais sensíveis, os relatos dos respondentes (grifados em itálico) e o diálogo com autores. Para começar, a primeira respondente é moradora de um pequeno município, Santo Antônio das Missões, que fica na região noroeste do estado do Rio Grande do Sul, estado bem ao Sul do Brasil.

"A relação das pessoas ficou mais distante fisicamente, porém mais próxima emocional e digitalmente. Ocorreram algumas transformações, principalmente no âmbito digital, que proporcionou um caminho alternativo para a comunicação com os clientes e parceiros comerciais. No que se refere especificamente a turismo, ocorreu queda no fluxo de pessoas devido as restrições impostas para conter o avanço da Pandemia COVID-19, observando isso tanto como turista quanto comerciante” (S. B., Santo Antônio das Missões-RS, 63 anos, comerciante).

A fala da moradora ajuda a refletir sobre a ambiguidade do papel das tecnologias, na interação das pessoas, especialmente em tempos de Pandemia do COVID-19. Monteiro (2017: 114) pontua que os dispositivos móveis e as Mídias Digitais, similares entre si são "[...] expansões do corpo, da mente e da alma humana capazes de promover interações biotécnicas ampliadoras das capacidades dos seres humanos". Nesse sentido, esses dispositivos podem provocar interações entre os sujeitos, ainda mais com a pandemia, que restringe o contato. Tem-se, aqui, portanto, um dos convites a repensar hábitos, assim como a rever a noção de corpo, considerando-a em sentido mais amplo, conforme estamos propondo.

O próximo respondente é morador da cidade de Santo Ângelo, que integra a região dos Sete Povos das Missões.

"Eu percebi que a relação de trabalho mudou um pouco, senti o distanciamento das pessoas que antes conversávamos e para algumas pessoas parece que chegar perto, mesmo de máscara, é algo estranho. Na maioria dos colegas de trabalho e 
com clientes há aquela sensação de estranheza até pelo fator de não ter o toque e a aproximação. Quanto ao turismo, aqui na cidade decaiu um pouco, teve lojas fechando as portas, nosso turismo não é tão grande, mas foi impactado ainda mais” (A. L., Santo Ângelo-RS, 39 anos, administrador).

O morador, ao perceber essa relação de estranheza entre as pessoas, dialoga com o pensamento de Crema sobre a mudança nos modos de viver e interagir fazendo uma reflexão para alterar as ações: "Mudar o mundo é mudar o modo de olhar... Necessitamos, também, de uma escola da Escuta. Escutar antecede compreender. Precisamos transcender esta crise ab-surda, esta surdez diante dos alaridos e canções da realidade" (2020).

A estranheza sentida pelos sujeitos em uma situação totalmente nova, como é o caso do COVID-19, é até compreensível para abrupta e necessária mudanças de hábitos. Vale ressaltar, no entanto, que o contexto é resultado de um processo, em que já se instauravam distorções nas relações, ao longo dos anos, e entremeava sujeitos e lugares, num desrespeito ao ecossistema como um todo, impactando relações e desenvolvimento sustentável de lugares turísticos.

A próxima respondente é moradora de Santa Rosa, na Região Noroeste do Rio Grande do Sul.

"Essa pandemia veio para criar novos caminhos e oportunidades para as pessoas reinventarem o modo de viver e ver a vida. Para mim o maior desafio foi criar possibilidades de atingir meus objetivos enquanto educadora e envolver as famílias nesse processo. Trabalhei muito mais do que se estivesse em sala de aula e acredito que os pais que se dedicaram em realizar as atividades com seus filhos tiveram enormes ganhos afetivos e cognitivos. Aqui em Santa Rosa, no Rio Grande do Sul, o turismo da cidade sofreu um enorme desgaste devido ao controle estabelecido pela pandemia. Infelizmente acredito que todos sofremos perdas nessa pandemia em vários sentidos, com ela também muitos aprendizados positivos e negativos também. Como professora de Educação Infantil sei que existem experiências que só se concretizam com as vivências e essas ficaram bem limitadas. E ainda seguem por tempo indefinido” (A. C., Santa Rosa-RS, 45 anos, professora).

A narrativa da moradora demonstra que a pandemia provoca uma reinvenção, necessária a todos, nos modos de viver e interagir, para que se possa conviver e transformar lugares turísticos. Dizeres como esse, expressos na fala da moradora, são facilmente assimilados com os dizeres de Capra em que devemos pensar como um todo para que possamos avançar, entrelaçados pelo bem comum: "Todos os seres vivos são membros de comunidades ecológicas ligadas umas às outras numa rede de interdependências. Quando essa percepção ecológica profunda torna-se parte de nossa consciência cotidiana, emerge um sistema de ética radicalmente novo" (2006: 19).

A respondente seguinte é moradora de Farroupilha, outro município da Serra Gaúcha.

"Na minha profissão de educadora física essa onda que está acontecendo fez com que as pessoas se fechassem dentro de casa e dentro de si; não deram muita atenção à falta de movimentação física, ao exercício; e que agora vem dando seus resultados negativos. Mas por outro lado, a reflexão se fez presente. Aos mais afortunados de empatia pela vida, foi o momento de encontrar-se com seu 'Eu interior', buscar respostas e aprendizados através da dificuldade. Pecamos muito no 
que se refere ao turismo em minha cidade, (Farroupilha) lugares fabulosos não são divulgados como deveriam. Temos estruturas para fazer o mesmo que cidades vizinhas fazem para atrair turistas e, não é feito" (M. F., Farroupilha-RS, 54 anos, educadora física).

No relato da moradora, o destaque para a falta de autocuidado. Ela ressalta que é importante pensar que corpo e mente estão interligados. Se bem cuidados, ambos podem trazer resultados que beneficiam, inclusive, as relações com os outros e com o lugar de moradia. Essa reflexão é capaz de levar a um estado constante de observação e percepção de si, impactando também no turismo da localidade. A reflexão pode trazer uma redescoberta de si mesmo, no sentido de propor, aos próprios sujeitos e ao lugar, o acionamento de uma atenção reflexiva, um outro olhar em que está envolvido, especialmente, o cuidado. Esse pensar vem ao encontro do que diz Lima (2009: 327): "O auto reconhecimento possibilitaria a libertação dos condicionamentos habituais que escravizam o desenvolvimento mais amplo do potencial humano e ao mesmo tempo traria como subsídio uma certa harmonia entre o estado interno do indivíduo e o meio ambiente".

A próxima respondente é de Caxias do Sul, cidade central da Serra Gaúcha.

"A pandemia acentuou e intensificou as dinâmicas prévias. Onde antes já havia, a cooperação, colaboração e confiança tornaram-se maiores. Da mesma forma, aumentaram as dificuldades de relacionamento, desconfiança e egoísmo que já se faziam presentes. As características pessoais de empatia e preocupação/cuidado com o próximo, bem como de individualismo e priorização das próprias necessidades em detrimento do bem comum tornaram-se mais evidentes. $O$ abraço, beijo e toque cessaram, cabendo refletir se haverá impacto a curto/médio/longo sobre a nossa cultura, tão adepta às expressões afetivas mediadas pelo contato físico. Quanto ao turismo, de forma empírica, pressuponho que tenha havido alterações, tanto na procura pela cidade quanto na forma de agir das pessoas. Acredito que a procura tenha diminuído significativamente e que o comportamento tenha se tornado mais contido, menos exploratório, leve e espontâneo, empobrecendo a experiência do turismo, que ao normal é sempre tão rica. Também imagino que tenha imposto à cidade um reinventar-se em busca de formas alternativas de manter-se como roteiro turístico para os visitantes, independente da pandemia” (C. D., Caxias do Sul-RS, 38 anos, psicóloga).

Ao relatar que as relações foram fragilizadas no contexto pandêmico, a moradora enfatiza que é importante rever características de afastamento, que já existiam antes da COVID-19. Com isso, sua fala convida a (re)pensar novos hábitos, para fortalecer vínculos na convivência. Dessa forma, pode-se dizer que há uma esperança, então, de modificação do corpo-ser humano. Aliás, a esperança é algo que necessita nos acompanhar porque acreditar que haverá uma mudança de consciência é importante. É o que pensadores de diversas áreas estão sinalizando - da Cosmologia, passando pela Neurociência, Comunicação, Turismo, Filosofia. A ressalva, no entanto, é que a esperança não pode ser estática. Temos que ter esperança, fazendo a nossa parte, entrelaçados com outros sujeitos e comprometidos com o planeta. Baptista (2019: 66) corrobora, dizendo que "segundo Maturana (1998), o amor é o reconhecimento do outro como legítimo outro na convivência e, por isso mesmo, se constitui na base constituidora dos laços sociais". A autora ainda recomenda que, "[...] para a produção de narrativas turísticas, ter como base o pressuposto amoroso, que ensina a 
respeitar o outro e a investir na convivência, como modo de consolidar laços e de valorizar as condições de interação" (Baptista, 2019: 66). Além disso, Capra e Henderson (2020) trazem a reflexão para pensar ecossistemicamente quando dizem que "o planeta nos mostrou a importância primordial de compreendermos nossa situação a partir de sistemas inteiros, identificados por alguns pensadores visionários já em meados do século XIX”. Faz-nos respirar e (re)pensar em mudar os hábitos pela sobrevivência humana e também pela sobrevivência do planeta.

A moradora de Brusque, em Santa Catarina, é a próxima a expor o seu relato.

"Meu trabalho acabou impactando muito e aí com a pandemia eu acabei dando mais atenção ao marketing digital, porque eu vi que era um nicho de mercado que ia começar a encorpar e que ia começar a ser bem direcionado para esse universo digital que de fato foi. Então na realidade a pandemia acabou direcionando o meu trabalho. Na realidade transformou. Em relação ao Turismo, aqui em Brusque existe muito turismo de negócios né, que é o turismo de compras. Então com certeza foi impactado tanto aqui na região como na cidade porque os ônibus pararam de vir, né, por conta da pandemia. E eu como turista né, porque eu tô aqui há pouco tempo, eu já vinha num processo de fazer mais turismo para conhecer mais a minha região, conhecer as opções, porque a gente tem tanto o turismo das praias como aqui na região que tem cachoeiras, as matas. E eu como turista né, como pessoa que gosta de explorar lugares diferentes, eu direcionei muito o meu turismo para essa região mais de mata, de sair um pouco da praia, da orla, que é onde tem muita aglomeração e fui buscar aqui em cidades menores, no interior, e buscar lugares mais afastados, com menos pessoas procurando é visitar esses lugares” (L. M., Brusque-SC, 42 anos, consultora de moda e marketing).

A moradora contempla a possibilidade de reinvenção em tempos de pandemia, buscando olhar para dentro de si, visando ampliar o escopo de criatividade e almejando superar os desafios impostos pelo desconhecido. Nesse contexto, é notável também dizer que há muitos corpos-humanos que se reinventaram com a pandemia. Em alguns casos, isso ocorreu de forma surpreendente, pois os sujeitos redescobriram um talento que ainda não tinham explorado. Outros foram obrigados a se reinventar, mas, mesmo assim, tiveram sucesso na nova caminhada.

A vida é sempre um desafio e está na condição humana essa reinvenção, tanto quanto a adaptação com mudanças. Crema (2020) faz lembrar que "[...] nós não nascemos humanos; nós nos tornamos humanos, através de um processo de autorrealização que exige um enorme investimento de tempo e de energia, em trilhas evolutivas". Nesse sentido está em nós, corpos-vivos-humanos, alterar o pensar desse corpo que habita, dos hábitos, do olhar sobre o território habitado e do olhar sobre o futuro do Turismo frente à Pandemia COVID-19.

Para algumas pessoas ou grupos, o processo de transformação talvez demore um pouco, mas há a necessidade de reinventar sujeitos e lugares turísticos, no sentido de que haja vida futura. Vale ressaltar, contudo, que, para que isso aconteça, as palavras de Merleau-Ponty soam muito bem, ajudando a (re)pensar: "A verdadeira filosofia é reaprender a ver o mundo" (2011: 19). E nesse (re)pensar, Krenak (2019) também atenta para que modifiquemos nosso olhar, desestabilizando o que já está padronizado, para abrir possibilidades para outras percepções.

Diante das reflexões inerentes à Pandemia COVID-19 e das narrativas deste texto, podemos nos questionar: A terra irá se recuperar e nós corpos-vivos-humanos? Essa é uma 
indagação pertinente para (re)pensar hábitos e turismo no pós-pandemia. Sabemos, ademais, que, existem sinalizadores importantes, para a retomada. Assim, trata-se de uma questão de escolha. É tudo uma questão de olhar. "Mas faz uma distinção no ver, em que a palavra visão tem dois significados: o ver concreto, ou a faculdade de ver pelo intelecto ou pelo olho; e a própria ação do ver, o ato da potência de ver" (Novaes \& Aguiar, 1988: 17-18).

A respondente seguinte é moradora de Curitiba, capital do Paraná, um dos três Estados que compõem a Região Sul do Brasil.

"O relacionamento entre colegas $e$ alunos no setor da educação foi altamente comprometido com a situação da pandemia. No entanto foram realizadas atitudes em Curitiba para o aprimoramento da rotina escolar não presencial. Em se tratando de turismo, tenho observado entre as colegas trabalho que houve um certo aumento para as viagens curtas antes da alta temporada. De setembro a dezembro eu realizei quatro viagens curtas de carro, até às praias de Santa Catarina, dando preferência as mais retiradas, estadias em kitnets, observando as medidas de distanciamento $\boldsymbol{e}$ higiene. Foi o periodo que mais realizei viagens. Observei durante essas viagens que a maioria dos grupos familiar de turistas eram com crianças em idade escolar, ou avós de meia idade com netos e mães com crianças. Foi uma observação que acredito ter sido devido a pandemia, visto que alguns profissionais poderiam realizar as atividades remotas" (S. N., Curitiba-PR, 50 anos, professora).

É possível perceber nesse relato que as relações, comprometidas pela pandemia -e já em crise antes da pandemia-, necessitam ser revisitadas, para serem enfrentadas em qualquer tempo de crise, e isso diz respeito às relações tanto pessoais quanto profissionais. Nesse interim, é possível refletir, com as palavras de Lima, a respeito da comunicação e do jornalismo que coadunam na reflexão com a crise pandêmica e sobre mudar os hábitos: "Descobrimos que os nossos instrumentos convencionais de percepção e entendimento são insuficientes. Por isso a necessidade urgente da revisão profunda dos alicerces e valores que condicionam nosso modo de enxergar a realidade" (2009: 342). Nesse sentido, aprender sobre nós mesmos, perceber o outro e o lugar onde estamos, faz-se importante para fortalecer tanto as relações, quanto a convivência, a comunicação e o turismo.

Ao finalizar os relatos dos moradores, é possível dizer que, em grande maioria, as relações cotidianas, profissionais e turísticas sofreram alterações na convivência, fragilizando a todos. Pode-se dizer, também, que foram perceptíveis, nas 'com-versas' com moradores, sinalizadores de ações de amor, amorosidade, que ajudaram a dar continuidade na incerteza pandêmica. Dessa forma, para que possamos avançar, propondo outro turismo póspandemia, conscientemente e responsável ecosssistemicamente, é importante repensar os hábitos, com a compreensão de que somos todos um ecossistema somente.

\section{RESULTADOS E DISCUSSÃO}

Na proposição trazida, os resultados e as discussões ficam por conta de refletir de forma sensível a comunicação e o turismo e refazer os olhares. Olhar de maneira diferente é primordial para a sobrevivência no pós-pandemia, já que nas transversalidades das narrativas sensíveis a imagem tem importância crucial. Dessa forma, Martine Joly (2004: 14) fala sobre a imagem que é "anunciada, comentada, adulada ou vilipendiada pelos próprios media, a imagem torna-se então sinônimo de televisão e de publicidade". A imagem do que muitos 
veem então, necessita de ressignificação, de tal forma que ajude a fazer outra comunicação, outro turismo. Interessante, os ensinamentos de Donis Dondis (2007: 51) sobre alfabetismo visual. A autora também reflete que "Os elementos visuais constituem a substância básica daquilo que vemos, e seu número é reduzido: o ponto, a linha, a forma, a direção, o tom, a cor, a textura, a dimensão, a escala e o movimento". Atenta Dondis que por mais que eles sejam reduzidos, são eles a matéria-prima das visualidades quando se trata de opções e combinações seletivas. Assim, aquilo que vemos é uma construção de várias formas de olhar, é também uma possível reconstrução. Por isso, também, as imagens têm sido tão importantes nas pesquisas Amorcomtur!.

Indo ao encontro desse pensar diferente, na vida, no profissional e também no turismo, é preciso refletir profundamente e mudar de atitudes. Baptista corrobora, dizendo que

"Na reflexão sobre o caráter desterritorializante do turismo, o texto também convida a pensar sobre as conexões de afeto, as intensidades abstratas, sobre o movimento interno e as novas conexões entre sujeitos e lugares, que passam a ressignificar as experiências e, nesse sentido, podem e devem se expressar em narrativas de escre'ver-se', de inscre'ver-se' e de reinvente'ar-se'!” (2019: 20).

Assim, podemos retomar a discussão sobre o corpo, lembrando que um corpo é um corpo que se transforma, desde o primeiro instante da vida. E ao longo da caminhada vai adquirindo formas e formatos. Vai criando corpo, se modifica, habita o espaço. Anseia por habitar o espaço externo em um convite para o desconhecido. E esse corpo vê, fala, comunica, se relaciona e passeia (de um lugar para outro no Turismo). Em um primeiro momento, ver, comunicar, relacionar-se e passear podem aparentar estar relacionados a processos particulares e subjetivos. Trata-se, contudo, de um engano. Sujeitos e lugares, com suas múltiplas dimensões de corpos, vivem entrelaçados, assim são forjados, vivem, sobrevivem, reinventam-se, autopoietizam. Desse modo, para pensar e (re)pensar os hábitos, agindo ecossistemicamente (pensar o todo e não as partes), é preciso ressignificar os modos de viver e interagir. Compreensível dizer que muito há de ser feito, de ser pensado, de ser modificado. Entende-se, aqui, então, que, para o pós-pandemia, há uma importância em construir 'tramas' que sustentem a vida, relações de amorosidade e autopoiese. E nessas transversalizações, incluem-se sujeitos e lugares e também o Turismo. Nas palavras de Monteiro (2017: 120), "somos, aparentemente, resultado do que evoluímos".

"Trama expressa entrelaçamento, trançados, enredamento de fios, fluxos, phyluns que se juntam e se amarram combinando um nó ou vários" (Baptista, 2020a: 1330-1331). Trama é também a teia da vida, gera novas brotações e combinações, nas palavras da autora, e nesse sentido, essa proposição se alinha ao pensamento de Fritjof Capra (2006), ao compreender a concatenação com o pensamento sistêmico. Para Capra, "entender a interdependência ecológica significa entender relações" (Capra, 2006: 233). E o autor ainda pontua que pensar dessa forma determina as mudanças de percepção que são características do pensamento sistêmico. É necessário pensar “[...] das partes para o todo, de objetos para relações, de conteúdo para padrão. Uma comunidade humana sustentável está ciente das múltiplas relações entre seus membros. Nutrir a comunidade significa nutrir essas relações" (Capra, 2006: 233). Desse modo, é possível compreender que não há uma rigidez na trama, ela é processual, quando seus fios escapam, abrem novas possibilidades de construções.

A trama é constituída então de uma rede de relações que tranversalizam o 'com-versar', que comunica de modo diferente e que é capaz de propor um outro turismo - pelo avesso, indo na contramão das relações impositivas e dos códigos capitalísticos pensando o 
ecossistema como um todo integrado. Pode-se dizer que a Pandemia do COVID-19 criou condições e demandas para repensar profundamente o encaminhamento da discussão sobre o Turismo. Bem como, a trama constituída com os resultados desse trabalho, através das narrativas de sujeitos, apontaram sinalizações que há urgência em reformar o pensamento e renovar atitudes para que a sobrevivência em todos os níveis aconteça.

\section{CONSIDERAÇÕES FINAIS}

As narrativas transversais sensíveis, com relatos de sujeitos em lugares turísticos, transversalizando temáticas: corpo que habita, hábitos, território habitado e futuro do Turismo frente à Pandemia COVID-19, que foram apresentadas neste texto, apresentam diversos sinalizadores. Primeiro, podemos destacar a necessidade de conscientização quanto ao fato de que somos todos parte de um grande ecossistema planetário -pessoas, animais, plantas, meio ambiente-, e que temos todos responsabilidades, que vão além do ecossistema social; é uma responsabilidade ecossistêmica. É por nós. É pelo planeta. É por todos. Infelizmente, também há sinalizadores de que boa parcela de sujeitos continuará não se importando com o 'outro' e com o ecossistema, porque uma mudança de paradigma leva tempo.

Depois, pode-se dizer, conforme os relatos, que a fragilidade das relações parece estar comprometida com o afastamento das pessoas. E de maneira contrária, ações que envolvem a empatia, a generosidade e o amor foram percebidas e possibilitaram mais afago aos diversos sujeitos que estavam em vulnerabilidade. Dessa forma, para que possamos avançar, propondo outro turismo pós-pandemia, consciente e responsável ecosssistemicamente, é importante agenciar a potencialidade de amorosidade e autopoiese dos sujeitos.

Arriscamos utilizar uma metáfora para dizer que o caminho está no coração, pois, o coração é um órgão que, ramificado com outros vários órgãos, como um rizoma (Deleuze \& Guattari, 2010), é capaz de criar extensões de contato e de sobrevivência, não só para si, mas para o todo, entrelaçando outros órgãos. Nesse pensar, podem ser criados outros contornos, outros delineamentos, em que as percepções e os olhares, nas relações, na comunicação e no turismo, podem se modificar, sendo capazes de uma reinvenção.

\section{REFERÊNCIAS}

Baitello, N. Jr. (2002). As Quatro Devorações. Iconofagia e Antropofagia na Comunicação e na Cultura. Anais da Associação Nacional dos Programas de Pós-Graduação em Comunicação, Compós, Rio de Janeiro, RJ, 11. Recuperado em 20 janeiro, 2021, de http://www.compos.org.br/data/biblioteca_735.pdf

Baptista, M. L. C. (1996). Comunicação: Trama de Desejos e Espelhos. Canoas: ULBRA.

Baptista, M. L. C. (2000). O sujeito da escrita e a trama comunicacional. Um estudo sobre os processos de escrita do jovem adulto como expressão da trama comunicacional e da subjetividade contemporânea. 440. fls. Tese (Doutorado em Ciências da Comunicação). Escola de Comunicações e Artes, Universidade de São Paulo São Paulo, Brasil.

Baptista, M. L. C. (2014a). Amorosidade comunicacional no turismo: dispositivo para hospitalidade em tempos de complexidade. In: M. M. C. Santos \& I. Batista (Orgs.). Laços Sociais: por uma epistemologia da hospitalidade. Caxias do Sul, RS: EDUCS. 
Baptista, M. L. C. (2014b). Caosmose, desterritorialização e amorosidade na comunicação. Questões Transversais - Revista de Epistemologias da Comunicação, 2(4), 98-105. Recuperado em 15 fevereiro, 2021, de http://revistas.unisinos.br/index.php/questoes/article/view/9625/PDF

Baptista, M. L. C. (2014c). Cartografia de Saberes na pesquisa em Turismo: Proposições Metodológicas para uma Ciência em Mutação. Rosa dos Ventos - Turismo e Hospitalidade, 6(3), 342-355. Recuperado em 10 fevereiro, 2021, de http://www.ucs.br/etc/revistas/index.php/rosadosventos/article/view/2647

Baptista, M. L. C. (2019). Afetivações, amorosidade e autopoiese: sinalizadores para narrativas sensíveis de destinos turísticos, em perspectiva ecossistêmica. In: D. A. Soster \& F. Piccinin (Orgs.). Narrativas midiáticas contemporâneas: sujeitos, corpos e lugares. Santa Cruz do Sul/RS: Catarse.

Baptista, M. L. C. (2020a). “Amar la trama más que el desenlace!”: Reflexões sobre as proposições Trama Ecossistêmica da Ciência, Cartografia dos Saberes e Matrizes Rizomáticas, na pesquisa em Turismo. Revista de Turismo Contemporâneo, 8(1), 41-64.

Baptista, M. L. C. (2020b). Trama de 'floresceres' no ensino da ciência. Percursos orientados por entrelaços de amorosidade, confiança e alegria, em processos autopoiéticos de ensino e produção da ciência. RIAEE - Revista Ibero-Americana de Estudos em Educação, 15(3), 1322-1342. Recuperado em 10 março, 2021, de https://periodicos.fclar.unesp.br/iberoamericana/article/view/13623

Beni, M. C. \& Moesch, M. (2017). A teoria da complexidade e o ecossistema do Turismo. TurismoVisão e Ação, 19 (3), 430-457. Recuperado em 6 março, 2021, de https://siaiap32.univali.br/seer/index.php/rtva/article/view/11662/6706

Capra, F. (1991). O Ponto de Mutação. A Ciência, a Sociedade e a Cultura Emergente. (12a ed.). São Paulo: Cultrix.

Capra, F. (2006). A Teia da Vida. Uma Nova Compreensão dos Sistemas Vivos. São Paulo: Cultrix.

Capra, H. (13 de julho de 2020). Hazel. Fritjof Capra: A pandemia vista de 2050. Fronteiras do Pensamento. Recuperado em 15 março, 2021, de 2050? fbclid=IwAR1GrQWYgG8Xa9BjpMKAiBBNSopGNA6lbze135CKoBX8XyNrZ7xIwnC mcgY

Crema, R. (1989). Introdução à Visão Holística. Breve Relato de Viagem do Velho ao Novo Paradigma. São Paulo: Summus.

Crema, R. (2020). Inteligência integral: O desafio transdisciplinar. Roberto Crema. Recuperado em 20 março, 2021, de https://robertocrema.com.br/inteligencia-integral-o-desafio-transdiciplinar/

Deleuze, G., \& Guattari, F. (1996). Mil platôs: capitalismo e esquizofrenia. Rio de Janeiro: Ed. 34.

Deleuze, G., \& Guattari, F. (2010). O anti-édipo: capitalismo e esquizofrenia. São Paulo: Editora 34.

Dondis, A. (2007). Sintaxe da linguagem visual. (3a ed.). São Paulo: Martins Fontes.

Guattari, F., \& Rolnik, S. (1996). Micropolitica: Cartografias do desejo (4a ed.) Petrópolis: Vozes.

Joly, M. (2004). Introdução à análise da imagem. (7a ed.). Campinas: Papirus.

Krenak, A. (2019). Ideias para adiar o fim do mundo. São Paulo: Companhia das Letras.

Lima, E. P. (2009). Páginas ampliadas: o livro-reportagem como extensão do jornalismo e da literatura. (4 ed.). São Paulo: Manole.

Lima, E. P. (2013). Escrita Total - O Método. São Paulo: Clube dos Autores.

Lima, E. P. (2020). Comunicação construtiva para uma sociedade consciente - Introdução. Webonar. EPL - Edvaldo Pereira Lima. (5m33s.). Recuperado em 10 março, 2021, de https://www.edvaldopereiralima.com.br/comunicacao-construtiva-para-uma-sociedadeconsciente/

Marcondes, C. F. (2010). O princípio da razão durante: comunicação para os antigos, a fenomenologia e o bergsonismo. Nova Teoria da Comunicação, volume III, tomo I. São Paulo: Paulus.

Martinez, M. (2012). Narrativas de viagem: escritos autorais que transcendem o tempo e o espaço [Versão eletrônica], Revista Brasileira de Ciências da Comunicação - Intercom, 35(1), 35-52. $\begin{array}{lllll}\text { Recuperado em } & 16 & \text { julho, } & 2020 & \text { de }\end{array}$ http://www.portcom.intercom.org.br/revistas/index.php/revistaintercom/article/view/1097/994 
Martinez, M.; Heidemann, V. (2019). Jornalismo literário: afeto e vínculos em narrativas. Lumina, PPGCOM - UFJF, 13(1), 4-14. Recuperado em 3 março, 2021, de https://periodicos.ufjf.br/index.php/lumina/article/view/26055/14814

Maturana, H. R. (1998). Emoções e linguagem na educação e política. Belo Horizonte: UFMG.

Maturana R. H., \& Varela G., F. J. (1997). De máquinas e seres vivos: autopoiese e a organização do vivo (3a ed.). Porto Alegre: Artes Médicas.

Merleau-Ponty, M. (2011). Fenomenologia da percepção. São Paulo: Martins Fontes.

Monteiro, G. V. (2017). Mídias digitais e as tecnologias da sobrevivência. Paulus, São Paulo, 1(1), 109-121. DOI: http://dx.doi.org/10.31657/rcp.v1i1.13. Recuperado em 15 março, 2021, de https://fapcom.edu.br/revista-paulus/index.php/revista-paulus/article/view/13/13

Monteiro, G. V. \& Colferai, S. A. (2011). Por uma pesquisa amazônida em Comunicação: provocações para novos olhares. In: Malcher, M., Seixas, N., Lima, R.,\& Amaral Filho, O. (Eds.). Comunicação midiatizada na e da Amazônia. Belém: FADESP.

Morin, E. (1991). Introdução ao pensamento complexo. São Paulo: Instituto Piaget.

Morin, E. (2004). Os sete saberes necessários à educação do futuro. São Paulo: Cortez.

Morin, E. (2012). A cabeça bem feita: repensar a reforma, reformar o pensamento. Rio de Janeiro: Bertrand Brasil.

Morin, E. (2013). Ciência com Consciência. (15a ed.). Rio de Janeiro: Bertrand Brasil.

Novaes, A., \& Aguiar, F. (c1988). O olhar. São Paulo: Cia. das Letras.

Prigogine, I. (2001). Ciência razão e paixão. In: Carvalho, E. A., Almeida, M. C. (Orgs). Ciência razão e paixão. (E. A. Carvalho; Isa Hetzel, Trad). Belém, Pará: Eduepa.

Reis, C. (2016). Entrevista: Humberto Maturana e a importância do amor. Casa.com.br. recuperado em 21 março, 2021, de https://casa.abril.com.br/bem-estar/entrevista-humberto-maturana-e-aimportancia-do-amor/

Rolnik, S. (2011). Cartografia sentimental: transformações contemporâneas do desejo. (2a ed.). Porto Alegre: Sulina; Editora da UFRGS.

Sodré, M. (2006). As estratégias sensíveis: afeto, mídia e política. Petrópolis, RJ: Vozes.

Soster, D. de A., \& Piccinin, F. (2019). Narrativas midiáticas contemporâneas: sujeitos, corpos e lugares. Santa Cruz do Sul: Catarse.

TvPuc. (11 de outubro de 2013). Pensar e Fazer Arte - A corporeidade - as diferentes linguagens do corpo - 39. Entrevista com Prof. Dr. Norval Baitello Junior. [Vídeo] Youtube. https://www.youtube.com/watch?v=kyk7P XlLTg

Yázigi, E. (2001). A alma do lugar. Turismo, Planejamento e Cotidiano. São Paulo, Contexto.

\section{Breve currículo}

\section{Newton Fernades de Ávila}

Estudiante de doctorado en Turismo y Hospitalidad en la Universidad de Caxias do Sul. Máster en Turismo y Hospitalidad (UCS). MBA en Gestión de Personas (ANHANGUERA). Graduado en Comunicación Social - Relaciones Públicas (UCS). Becario científico CAPES Universidad de Caxias do Sul (BRASIL). Miembro de ¡Amorcomtur! Grupo de Estudios en Comunicación, Turismo, Amorosidad y Autopoiesis (CNPq-UCS). Experiencia de 21 años, en talleres sobre Prácticas de Reinvención del Ser. Brasil.

\section{Maria Luiza Cardinale Baptista}

Postdoctorada en Sociedad y Cultura de la Amazonía por UFAM. Doctora en Ciencias de la Comunicación por ECA / USP. Profesora e Investigadora del Programa de Postgrado en Turismo y Hostelería y de los cursos de Comunicación Social de la UCS. Editora de la 
Revista Conexión - Comunicación y Cultura - UCS. Coordinadora de AMORCOMTUR! Grupo de Estudio sobre Comunicación, Turismo, Amorosidad y Autopoiesis. Profesora colaboradora de la Universidad Federal de Amazonas (UFAM). Directora de la empresa Pazza Comunicazione. 